\title{
The Effects of FDI on Innovation Systems in Hungarian Regions: Where is the Synergy Generated?
}

\begin{abstract}
In this study, we show how internationalization and foreign-owned firms influence synergies in the regional innovation systems of Hungary. We first distinguish three innovation system functions (knowledge exploitation, knowledge exploration, and organizational control) operating in regions and study their interactions using entropy statistics. The functions and their interactions are measured by analysing the distribution of firms in terms of geographical location, organizational size (number of employees), technologies (NACE codes of the OECD), and ownership (foreign versus domestic share in registered stock) in the 2005. Synergy is defined as mutual information among the three dimensions; a fourth dimension is added in order to bring internationalization (FDI) into the model. The factor is relevant since the four-dimensional model explains the GDP contributions to regional development in Hungary, whereas the three-dimensional model does not. We find that regional innovation systems in Hungary are self-organized differently, in relation to a relatively small number of foreign firms. These firms have a large positive effect on synergy in regions between the Hungarian capital and the Austrian border. However, FDI has negative effects on domestic synergy in the lagging eastern and southern provinces of the country.
\end{abstract}

Keywords: regional innovation systems, innovation system function, synergy, entropy, foreign firms.

\section{Introduction}

Regional innovation systems (RIS) have been analysed in order to answer policy-oriented questions such as why innovation output, technological change, and consequently regional development differs across regions (Boschma-Frenken 2006, Cooke et al. 2004 MartinSunley 2007). The RIS literaturemainly refers to local institutions and milieu (Lundvall et al. 2002, Tödtling-Tripple 2005), local and sticky versus global and ubiquitous knowledge (Asheim-Isaksen 2002), university-industry collaborations (Etzkowitz-Leydesdorff 2000), and governance (Braczyk et al. 1998, Cooke 2001). One assumes that a wellfunctioning RIS provides proper grounds for synergistic co-operation between co-located organizations, firms, etc. (Cooke-Leydesdorff 2006).

a) Centre for Economic and Regional Studies, Hungarian Academy of Sciences, H-1112 Budapest, Budaörsi út 45., Hungary and International Business School Budapest, H-1031 Budapest, Záhony utca 7, Hungary. E-mail: lengyel.balazs@krtk.mta.hu

b) Amsterdam School of Communication Research, University of Amsterdam, 1001 NG Amsterdam, P.O. Box 15793, The Netherlands. E-mail: loet@leydesdorff.net 
Yet, it was repeatedly pointed out that multinational companies can be crucial players in regional systems (Biggiero 2007, Cantwell-Iammarino 1998, Dachs et al. 2008, Ferragina-Mazzotta 2014, Majumdar 2009). This is especially the case in Central and Eastern European countries that rely extensively on the performance of such companies (Inzelt 2008, Radosevic 2002). Therefore, in a country like Hungary where the vast majority of exports are carried by multinational companies, it is crucial to understand the specific role of multinational companies in regional economic development (Acs et al. 2007). The central question of this study concerns the effect of foreign-owned companies on regional innovation systems in the Hungarian economy.

Some argue that foreign firms were general sources of knowledge spillover and their presence generated positive local externalities beneficial to domestic firms in Hungary (Halpern-Muraközy 2007). In this sense, FDI can be considered as the major engine of regional development (Lengyel-Szakálné 2014). However, other papers (Békés et al. 2009) have shown that spillover effects have occurred only among foreign-owned companies and those Hungarian domestic firms that previously performed at relatively higher levels of productivity. Thus, relatively more developed environments might have benefited more from the presence of foreign companies and less spillover can be expected from foreign firms in lagging regions (Lengyel-Leydesdorff 2011).

In this study, we calculate the effect of foreign firms on synergy in RIS using indicators derived from complex systems theory and entropy statistics (Leydesdorff et al. 2006, Leydesdorff-Fritsch 2006, Ulanowicz 2006 and 2009). A previous study focusing on Hungary and using the same methodology found regionally diverse economies, in which the capital, the western regions and eastern regions follow different development paths (Lengyel-Leydesdorff 2011). As a question for further research, we proposed the study of the role of FDI in causing this regional divergence. In this study, we had access to a new database of better quality, and used this for the four-dimensional extension of the synergy indicator in order to quantify the effects of foreign-owned firms.

We find that a North-West South-East divide prevails concerning the effect of foreign firms on the synergy in regions. Foreign firms have positive effects on the synergy in innovation systems only in some relatively developed regions; meanwhile foreign firms disturb the synergy in lagging regions. The results suggest that the innovation systems of relatively developed areas have been re-structured by foreign-owned companies that generated new synergies in the regions. However, lagging regions are found to be selforganized in terms of domestic firms; positive externalities of FDI might not prevail in these latter locations.

\section{Theoretical background}

Synergy measurement in regional innovation systems derived from the triple helix model of university-industry-government collaboration has led to heuristics when looking at regional economies (Leydesdorff et al. 2006, Leydesdorff-Fritsch 2006, StrandLeydesdorff 2013, Leydesdorff-Strand 2013, Leydesdorff-Sun 2009). The RIS synergy model follows Storper's (1997, at pp. 26 ff.) "holy trinity" theory. This argument emphasizes that interrelationships among three independent dimensions-technology, organization, and territory-shape regional economies. The three independent dimensions 
are depicted in Figure 1, but the organizational dimension of the "holy trinity" is replaced with economic exchange relations in our model (Lengyel-Leydesdorff 2011). The reason for including the category of economic exchange instead of organization, is that the interactions with other firms and the costs of this interaction influence the size and scope of the firm (Coase 1937). We use the latter two characteristics as proxies in our model.

Synergy of innovation systems functions

Figure 1

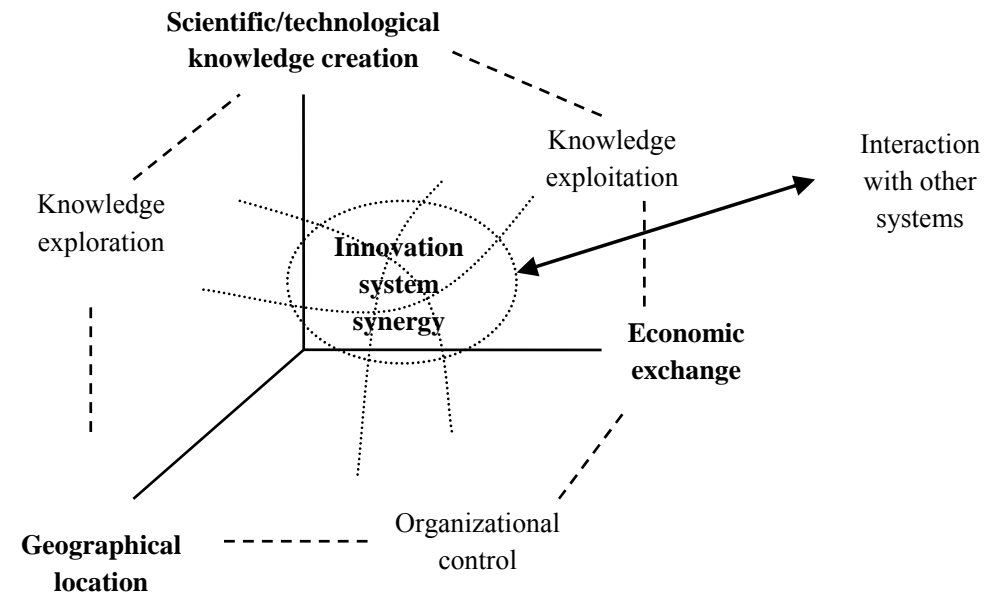

Source: adapted from Lengyel and Leydesdorff (2011, p. 681)

In Figure 1, we consider the first-order interaction terms between geographical location, economic exchange, and knowledge creation as three innovation system functions: (i) knowledge exploration, (ii) knowledge exploitation, and (iii) organizational control. These functions can be defined as interactions between two dimensions of innovation systems: technological-geographical, technological-economic, and geographical-economic, respectively. The system can self-organize synergistically when the three functions operate on each other in a second-order (or three-way) interaction; the result can be called RIS synergy that we measure as reduction of uncertainty. One may find an analogy between this RIS function synergy and the overlap of subsystems that is used to illustrate Storper's "holy trinity" or "triple helix" collaborations. However, synergy is quantifiable, which enables the calculation of the effects of the three functions, their interactions, and the underlying distributions. The measurement technique is explained in detail in Section 3. 
The functions are:

1. Knowledge exploitation is associated with the reuse of existing competencies and means (March 1991); at the systems level it represents the interface between economic welfare and technological knowledge creation (Gibbons et al. 1994). Knowledge exploitation does not necessarily depend on geographical locations because economic welfare is created at the level of global markets, even if certain technologies originate in single regions.

2. Knowledge exploration is associated with creating new alternatives (Baum et al. 2000); this function is place-dependent rather than market-dependent, because tacit knowledge is essential in creating new knowledge, and it relates significantly to places (Jaffe et al. 1993, Acs et al. 2002).

3. Organizational control is defined as collective institutions and mediating organizations that increase the probability of the emergence of new knowledge (Loasby 2001); these functions operate mainly in territorial units.

Because regional advantages can more easily be constructed in regions where synergy prevails among knowledge exploitation, knowledge exploration, and organizational control than in regions without such synergy, one can expect the former regions to outperform the latter in terms of innovation capacities. Theorizing RIS in terms of innovation system function synergies can provide new types of insights into regional economic systems. In addition to the possibility to mark regions, one of the most promising features of synergy measurement in terms of entropy is the opportunity to also quantify the effects of other major forces shaping the synergy in the regions (such as FDI).

However, regional innovation systems do not stand alone, but permanently interact with other RIS, as well as organizations at the level of national and international innovation systems (Tödtling-Trippl 2005). Furthermore, the extent of the interregional interaction between systems varies across regions (Asheim-Isaksen 2002). For example, decisions taken in distant headquarters of foreign-owned firms may take innovation system functions out of the region. Therefore, the relation with other systems has to be taken into consideration when measuring innovation systems synergy.

In the following sections, we show that a four-dimensional model, in which internationalization is additionally considered by means of foreign versus domestic ownership, explains the expected relation with GDP per capita at the regional level, whereas the three-dimensional model did not. This means that foreign ownership also has to be considered when calculating RIS synergy. However, a three-dimensional RIS synergy model will first be developed as a baseline to show in the next step how foreign firms have diverse effects on regional innovation systems. 


\section{Materials and Methods}

\section{Data}

To demonstrate the regionally diverse effects of FDI in Hungary, a firm level database is used that contains census type data from all sectors for $2005 .{ }^{1}$ According to the model specified above, one-, two-, three-, and four-dimensional firm distributions will be used to calculate RIS synergy. The four dimensions are:

1. technological specialization indicates the characteristics of technological knowledge creation (this is represented in the data by NACE 2 codes of firms) ${ }^{2}$;

2. geographical location of the company (NUTS 4 regions) ${ }^{3}$;

3. firm size proxies the dimension of economic exchange (this is captured by number of employees);

4. ownership structure captures the dimension of internationalization (foreign or domestic ownership based on registered stock).

We pursue the analysis in terms of economic sectors, and by exclusively using data for high- and medium-tech industries and knowledge intensive services (HTMTKIS). ${ }^{4}$ After this comparison, we focus on HTMTKIS sectors when calculating the effects of foreign firms because the majority of the foreign firms operate in these industries.

Foreign interest is attributed when $10 \%$ or more shares of the stocks of a firm are in foreign hands (HSCO 2007). We consider all these firms as foreign-owned even if domestic ownership is higher than foreign ownership in the firm. Company size reflects those categories that are generally used for economic analyses (Table 1). In 2005, companies were categorized into 20 Hungarian counties (NUTS 3 level) that contained 168 subregions (local administrative units, NUTS 4 level). We report the results at the county level.

Table 1

Number of firms in the analysis

\begin{tabular}{c|r|r|r|r}
\hline \multirow{2}{*}{$\begin{array}{c}\text { Number of } \\
\text { Employees }\end{array}$} & \multicolumn{2}{|c|}{ HTMTKIS } & \multicolumn{2}{c}{ All sectors } \\
\cline { 2 - 5 } & Domestic & Foreign & Domestic & Foreign \\
\hline 0 or unknown & 47,005 & 4,608 & 52,480 & 3,937 \\
$1-9$ & 59,330 & 2,698 & 100,886 & 6,359 \\
$10-19$ & 3,095 & 335 & 10,309 & 855 \\
$20-49$ & 1,800 & 333 & 5,743 & 757 \\
$50-249$ & 899 & 322 & 2,567 & 678 \\
250 or more & 134 & 173 & 314 & 180 \\
\hline \multirow{2}{*}{ Total } & $\mathbf{1 1 2 , 2 6 3}$ & $\mathbf{8 , 4 6 9}$ & $\mathbf{1 7 2 , 2 9 9}$ & $\mathbf{1 2 , 7 6 6}$
\end{tabular}

Source: own compilation.

1 Differently from this study, Lengyel \& Leydesdorff (2011) analysed only high- and medium-tech industries and knowledge-intensive services.

2 NACE is an abbreviation of Nomenclature générale des Activités économiques dans les Communautés Européennes.

3 NUTS is an abbreviation of "Nomenclature des Unités Territoriales Statistiques" (that is, Nomenclature of Territorial Units for Statistics). The NUTS classification is a hierarchical system for dividing up the economic territory of the EU.

4 Nace 2 codes for high-tech manufacturing: 30, 32, 33; medium-tech manufacturing: 24, 29, 31, 34, 35; knowledgeintensive services: 61, 62, 64, 65, 66, 67, 70, 71, 72, 73, 74, 80, 85, 92. 
Table 1 demonstrates the distribution of firms in the two dimensions of ownership and size. Firms without employees are left in the sample because spin-off companies can be included in this category. Firms with foreign interest are on average larger than domestic ones, and almost all large foreign-owned companies are in the high- and medium-tech industries, or knowledge-intensive services.

Firm distribution and GDP per capita in Hungarian counties, 2005

Figure 2

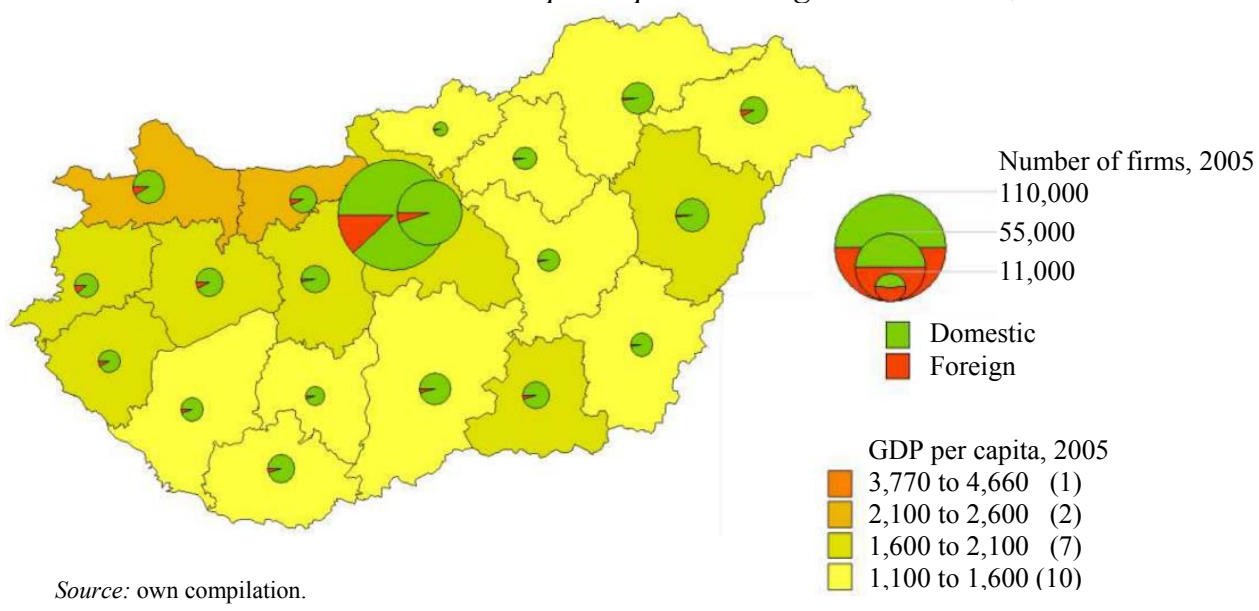

The regional distribution of firms by ownership category is depicted against GDP per capita in Hungarian counties in Figure 2. The relatively developed regions constitute one block situated in the northwest of Hungary between Budapest and the Austrian border. There are only a few foreign companies in each location, and developed regions do not differ from lagging regions in this sense. The only exception is Budapest, which counts for a large rate of foreign firms. We will demonstrate that foreign firms have positive effects on RIS synergy in relatively developed regions in the Northwest and a negative impact on synergy in lagging regions in the south and east of the country.

\section{Synergy measurement}

The measurement of synergy among innovation system functions in regions is based on entropy statistics developed within a complexity approach. In such an approach, and in accordance with evolutionary economic theorizing, uncertainty is considered as a fundamental characteristic of economic progress (Foster-Metcalfe 2001, Metcalfe-Foster 2004). Complexity measurement in economics usually focuses on agents and deals with the amount of information the agent needs for decision making and for overcoming uncertainty (Delorme 2001, Louca 2001). However, economic and regional systems can be different regarding this information demand because of general trust among people, collectively accepted rules, etc. that varies across systems. Therefore, we propose a method of complexity measurement that addresses uncertainty and the reduction of it, in particular, at a system level. 
Uncertainty can decrease along with growing redundancy at both the micro and macro levels, but not necessarily to the same extent. For example, when the knowledge of agents is overlapping, their expectations of each other's future actions are formed more easily; therefore, there is less uncertainty in a single action or micro level. In a similar manner, the overlap (that is, redundancy) between subsystems of RIS reduces uncertainty on a macro level because actors from different subsystems can understand each other more easily. Our model depicted in Figure 1 addresses this phenomenon with the use of innovation system functions; synergy among the three functions can reduce uncertainty prevailing in a system.

Uncertainty can be measured in bits using Shannon's (1948) formulas that were applied in economics (Delorme 2001) and geography (Johnston et al. 2000). Entropy is furthermore used for other purposes: since entropy takes a higher value if a distribution is even, it can also be used as an indicator of diversity. Furthermore, because probabilistic entropy can be fully decomposed into its components, it has also been used as the method for calculating related variety in regions (Frenken et al. 2007, Theil 1972).

Synergy in an innovation system can be measured as a reduction of uncertainty at the systems level, which is based on entropy calculation in three- and four dimensions introduced in the following subsection (Leydesdorff-Ivanova 2014, Mêgnigbêto 2014, Yeung 2008, p. 59.).

\section{Methodology}

The uncertainty contained in the distribution of a random variable $x\left(\sum_{x} p_{x}\right)$ is defined by Shannon (1948; cf. Theil 1972) as $H_{x}=-\sum_{x} p_{x} \log _{2} p_{x}$. Analogously, the uncertainty in a two-dimensional distribution can then be formulated as: $H_{x y}=-\sum_{x} \sum_{y} p_{x y} \log _{2} p_{x y}$. This uncertainty is the sum of the uncertainty in the two variables diminished with their mutual information as a measure of their co-variation. In the case of two dimensions, the uncertainty in the two potentially interacting dimensions $(x$ and $y)$ is reduced with the mutual information. Transmission or mutual information that captures this reduction of uncertainty is formalized in the case of two dimensions as follows:

$$
T_{x y}=\left(H_{x}+H_{y}\right)-H_{x y}
$$

In the limiting case that the distributions $x$ and $y$ are completely independent, $T_{x y}=0$ and $H_{x y}=H_{x}+H_{y}$. In all other cases $T_{x y}>0$, and therefore $H_{x y} \leq H_{x}+H_{y}$ (Theil 1972, p. 59.). In general, two variables determine each other in their mutual information $\left(T_{x y}\right)$, and condition each other otherwise. However, in the case of three interacting variables, there are two options: the three interacting systems may have a common interaction shared by all of them or not. In the latter case, the correlation among each two can be spuriously influenced by the third.

In the case of overlaps among three (or more) functions, synergy can be expressed by an information measure $\left(T_{\mathrm{xyz}}\right)$, which McGill (1954) derived from the Shannon formulas: ${ }^{5}$

$$
T_{x y z}=H_{x}+H_{y}+H_{z}-H_{x y}-H_{x z}-H_{y z}+H_{x y z}
$$

5 Both Yeung (2008, p. 59f.) and Krippendorff (2009, p. 200) noted that this information measure can no longer be considered as a Shannon-type measure because of the possible circularity in the information transfers. Shannon-type entropy measures are by definition linear and positive. Since the measure sums Shannon-type measures in terms of bits of information, its dimensionality is also bits of information, and therefore it can be used as a measure of uncertainty and uncertainty reduction, respectively. 
While the two-dimensional systems reduce uncertainty, the trilateral term in turn feeds back on this reduction and, therefore, adds another term to the uncertainty. The feedback can be so strong that the net result becomes negative, and thus uncertainty is reduced. The configuration of the system - distributions and their overlaps - determines the net result in terms of the value of $T_{x y z}$ (McGill 1954). We use $T_{x y z}<0$ as an indicator that the uncertainty is reduced to the extent that synergy is indicated. The value of $T_{X Y Z}$ measures the interrelatedness of the three sources of variance and the fit of the relations and correlations between and among them. $T_{X Y Z}$ has been used as an indicator of potential reduction of uncertainty in complex systems in many disciplines (Ulanowicz 1986, Jakulin 2005).

Analogously, it can be shown to follow for four dimensions:

$$
\begin{aligned}
& T_{W X Y Z}=H_{W}+H_{X}+H_{Y}+H_{Z}-H_{W X}-H_{W Y}-i_{X Y}-H_{W Z}-H_{Y Z}-H_{X Z}+ \\
& H_{W X Y}+H_{W X Z}+H_{W Y Z}+H_{X Y Z}-H_{W X Y Z}
\end{aligned}
$$

It can be shown that the sign of mutual information is reversed in the case of an even number of dimensions (Leydesdorff-Ivanova, 2014). This solves a technical problem about the sign in information theory (Krippendorff 2009), but does not affect the measurement or the reasoning.

As noted, the four dimensions under study in this paper are $(\mathrm{G})$ eography, (T)echnology, (O)rganization, and (I)nternationalization, and $T_{G T O}$ and $T_{G T O I}$ will accordingly be used to indicate the mutual information among them. Similarly to Equations 2 and 3, one can formulate as follows:

$$
\begin{gathered}
T_{G T O}=H_{G}+H_{T}+H_{O}-H_{G T}-H_{G O}-H_{T O}+H_{G T O} \\
T_{G T O I}=H_{G}+H_{T}+H_{O}+H I-H_{G T}-H_{G O}-H_{T O}-H_{G I}-H_{O I}- \\
H_{T I}+H_{G T O}+H_{G T I}+H_{G O I}+H_{T O I}-H_{G T O I}
\end{gathered}
$$

We have argued above that the synergy in innovation systems can be measured as the reduction of uncertainty among knowledge exploitation, knowledge exploration and organizational control. High negative values of $T_{G T O}$ indicate a higher reduction of uncertainty and, therefore, a more synergistic innovation system. The same logic can be followed when interpreting the values of $T_{G T O I}$; however, a higher positive value of the indicator means stronger synergy because the sign of the four-dimensional entropy is reversed as was explained previously.

When the basis of the logarithm is two, all values are expressed in bits of information. Therefore, our entropy measures are formal (probability) measures and thus independent of size or any other reference to the empirical systems under study. The sigma in the formula allows all information terms to be fully decomposed. This is a crucial advantage because it enables us to calculate the effects of certain subsystems (e.g., foreign firms) in the complex set of variables. ${ }^{6}$ The calculations were done by using a computer routine described in Leydesdorff et al. (2014) and available online at http://www.leydesdorff.net/software/th4/index.htm .

6 Note that the method remains within the limitations of complexity modelling according to Allen's (2001) taxonomy: it only assumes that (1) the borders of the system are defined; (2) actors and subsystems that interact within the economic system are identified; (3) behaviour of actors are comparable to the mean of actions. 


\section{Results}

Entropy values in the regions highly depend on the number of categories (e.g. NACE 2 classes, subregions, firm size categories) and on the number of firms in the region. Table 2 shows the one-dimensional entropies in order to illustrate differences among regions. The two-dimensional entropy, as well as two and three-dimensional mutual information values are normalized by the number of firms in the region.

The maximum entropy in the technological dimension is $\log _{2}(22)=4.459$; and $\log _{2}(6)=2.584$ in the organizational dimension (there are 22 technological and 6 categories in our sample) and it varies according to the number of subregions in terms of geographical distribution. The entropy values in both dimensions indicate a very even distribution among the regions: Hungarian counties are more or less equally diverse in terms of technological specialization $\left(H_{T}\right)$ and organizational structure $\left(H_{O}\right)$. However, regional economies are geographically more centralized in southern and eastern counties where regional universities and government organizations are located in centres of administration: $H_{G}$ reaches $44 \%$ in Baranya $\left(1,408 / \log _{2}(9) \times 100\right), 47 \%$ in Hajdú-Bihar $\left(1,495 / \log _{2}(9) \times 100\right), 52 \%$ in Borsod-Abaúj-Zemplén $\left(2,046 / \log _{2}(15) \times 100\right)$ and $53 \%$ in Csongrád counties $\left(1,497 / \log _{2}(7) \times 100\right)$ of the maximum entropy; whereas the indicator is above $60 \%$ in all of the remaining counties. This finding resembles a study focusing on Russian innovation systems, in which similar relationships were found between statecontrolled services and entropy statistics (Leydesdorff et al. 2015).

\section{Synergy in regional innovation systems}

Innovation systems synergy is defined as the interdependence between innovation system functions. These functions represent three different selection environments that operate in the system simultaneously and are measured by two-dimensional transmissions between one-dimensional firm distributions $\left(T_{T G}, T_{T O}, T_{G O}\right)$. The value of these indicators varies across Hungarian regions (see Table 2). $T_{T G}$ is highest values in Pest (that surrounds Budapest), Borsod-Abaúj-Zemplén (with the second largest town in the North-East), Fejér (former location of large IT multinationals), and Baranya (strong university location with relatively weak economy) counties. Budapest stands out in $T_{T O}$, it is followed by Pest County, Györ-Moson-Sopron (home of the automotive industry in the North-East), Borsod-Abaúj-Zemplén, and Bács-Kiskun (South of the capital). The majority of Hungarian counties with the highest values of $T_{G O}$ also appear to be at the top of the list in terms of $T_{T G}$ : Pest, Borsod-Abaúj-Zemplén, Győr-Moson-Sopron, Baranya.

The status of Budapest is contradictory in the hierarchy of Hungarian regions; being a capital city, it is counted as both a county and a subregion in the NUTS classification. Due to the taxonomy, $H_{G}$ equals zero in Budapest and consequently the value of $T_{T G O}$ is very close to zero. Thus, we decided to eliminate Budapest from the presentation of $T_{T G O}$ results by setting the value equal to zero. This is a common practice in Hungarian geographical analyses and we admit that Budapest would require a separate analysis. 


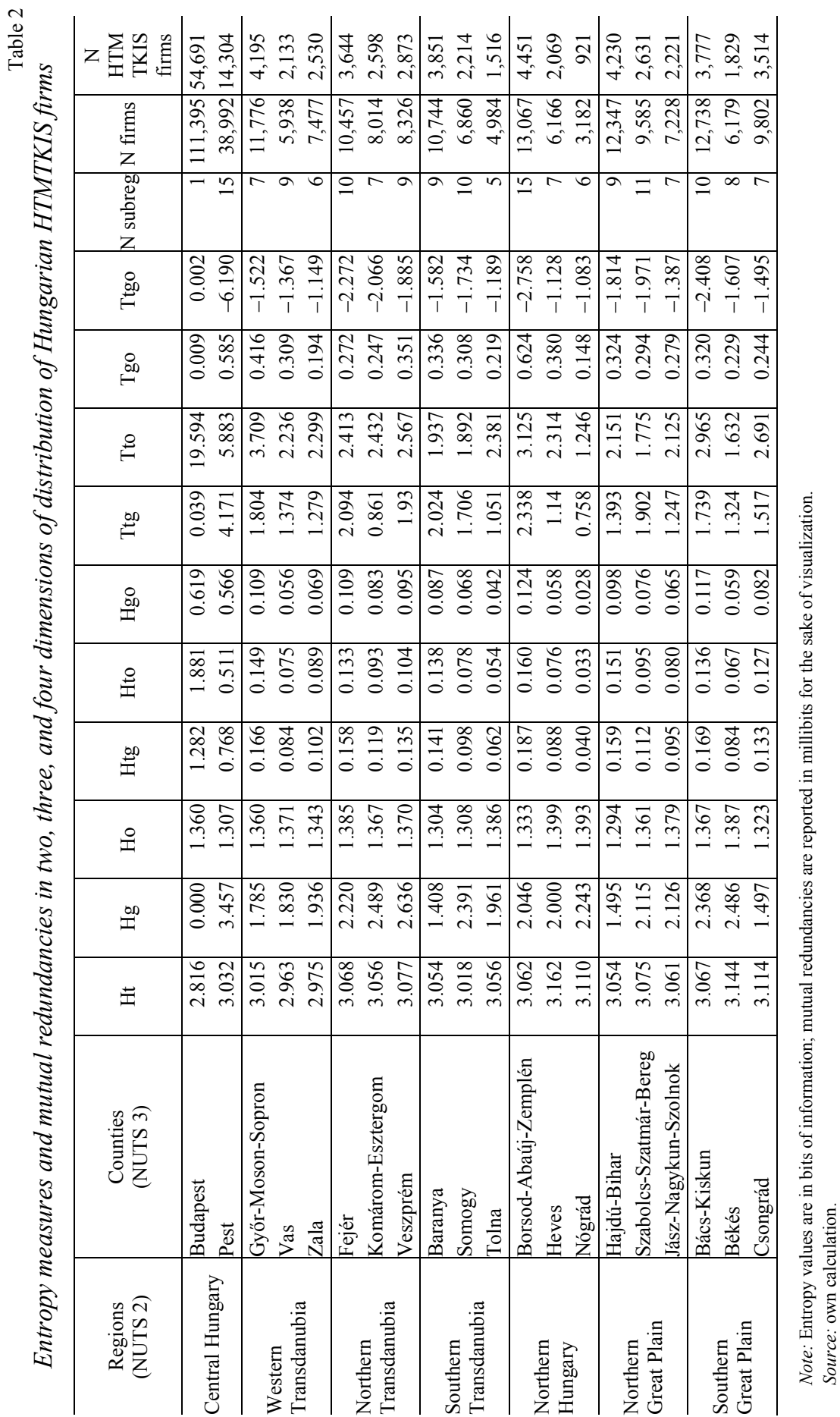


Innovation systems synergy in three dimensions,

Figure 3 the entire Hungarian economy versus HTMTKIS sectors, 2005

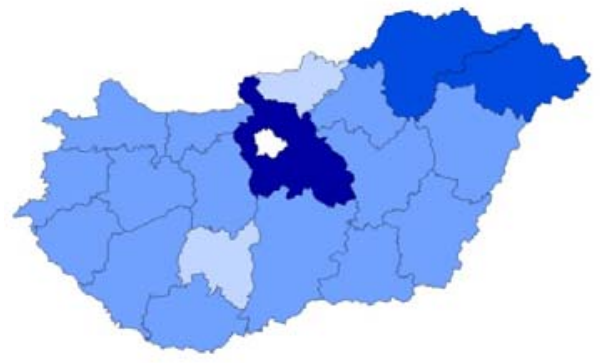

Ttgo in mbits

$$
0.0 \text { (1) }
$$

-1.5 to 0.0 (2)

-3.0 to $-1.5(14)$

-4.5 to -3.0 (2)

-6.1 to -4.5 (1)

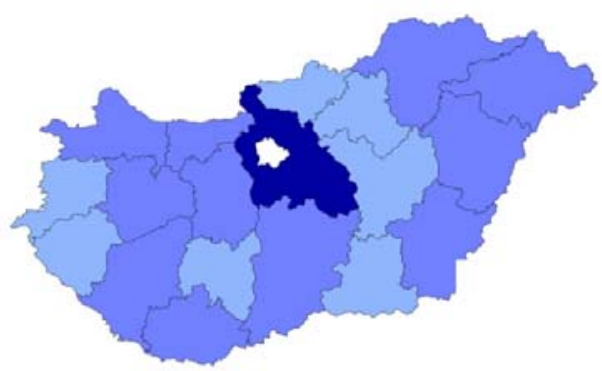

Ttgo in mbits, HT-MT-KIS sectors 0.0 (1)

-1.5 to $0.0(7)$

-3.0 to $-1.5(11)$

-6.2 to -4.5 (1)

Source: own compilation.

$T_{T G O}$ values calculated from Hungarian HTMTKIS firms' distribution suggest that innovation system functions overlap each other in the NUTS 3 regions of the country (see Table 2). One finds the strongest uncertainty reduction in Pest and Borsod-Abaúj-Zemplén regions, which also stood out in terms of all three innovation system functions. Regions that follow are Bács-Kiskun, Fejér that are among the top regions only in one innovation system function; and Komárom-Esztergom where the operating innovation system functions are not outstanding at all.

The national innovation system is organized around the capital's agglomeration; the synergy measured in the distribution of HTMTKIS firms is stronger in the western regions than in eastern regions; while there is no such an imbalance when synergy is measured in the distribution of firms from all economic sectors (Figure 3).

\section{Internationalization and mutual redundancy in four dimensions}

Innovation systems never operate in isolation but intensive interactions with global markets and their ability to attract investments are natural elements of success. Therefore, the dimension of internationalization is also included in our development model. Based on previous research regarding Hungarian economic transition (Lengyel-Leydesdorff 2011), one can expect that the additional dimension can be used to distinguish regions in this study. Indeed, the four-dimensional model fits better with the expectation based on the spatial distribution of GDP per capita and allows us to draw more sophisticated conclusions about RIS synergy in Hungary.

We classified firms into foreign-owned or domestic. We used the same procedure of uncertainty and redundancy calculation to measure the effect of internationalization in four dimensions as presented above for three dimensions. Contrary to the three-dimensional model, the mutual redundancy of four interacting functions (or any even number of 
dimensions) is indicated by a positive sign of transmission (Leydesdorff-Ivanova 2014, p. 389). Accordingly, a positive value of $T_{T G O I}$ marks a four-dimensional overlap, which confirms that the synergy is stable even after controlling for internationalization. Our results suggest that foreign-owned firms entered the region in those particular industrylocation-size combinations that favoured the existing synergy. Whereas negative values of $T_{T G O I}$ suggest that FDI and leading forces of innovation system synergy in the region did not co-occur.

Innovation systems synergy in four dimensions,

Figure 4 the entire Hungarian economy versus HTMTKIS sectors, 2005

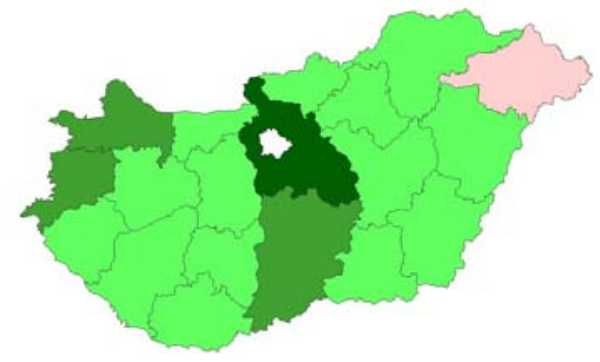

Ttgoi in mbits

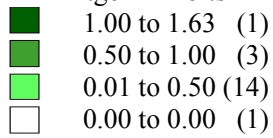

-0.26 to 0.00 (1)

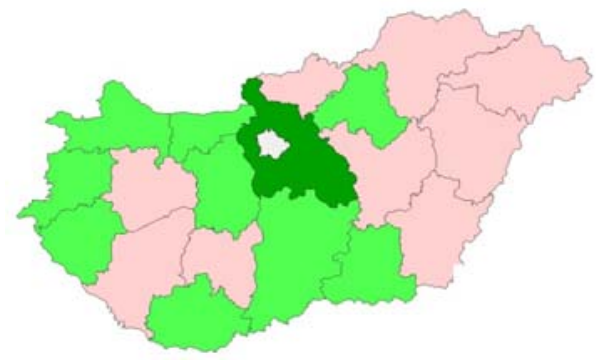

Ttgoi in mbits, HT-MT-KIS sectors

0.500 to 0.880 (1)

0.001 to $0.500(9)$

0.000 to 0.000 (1)

-0.210 to 0.000 (9)

Source: own compilation.

Four-dimensional mutual redundancy of Hungarian HTMTKIS firms takes a positive value only in half of the NUTS 3 regions (Table 3). The highest value of the fourdimensional overlap is in Pest County; a negative value of $T_{T G O I}$ occurs in one north-eastern county only. A sharp contrast between eastern and western regions emerges in this regard when looking at HTMTKIS sectors only. Similarly to the presentation of $T_{T G O}$ results, we depict the $T_{T G O I}$ value of Budapest separately. Note that the sign of $T_{T G O I}$ does not depend exclusively on the share of foreign firms in the economy. In other words, these findings show the four-dimensional distribution of firms and not their FDI intensity. 


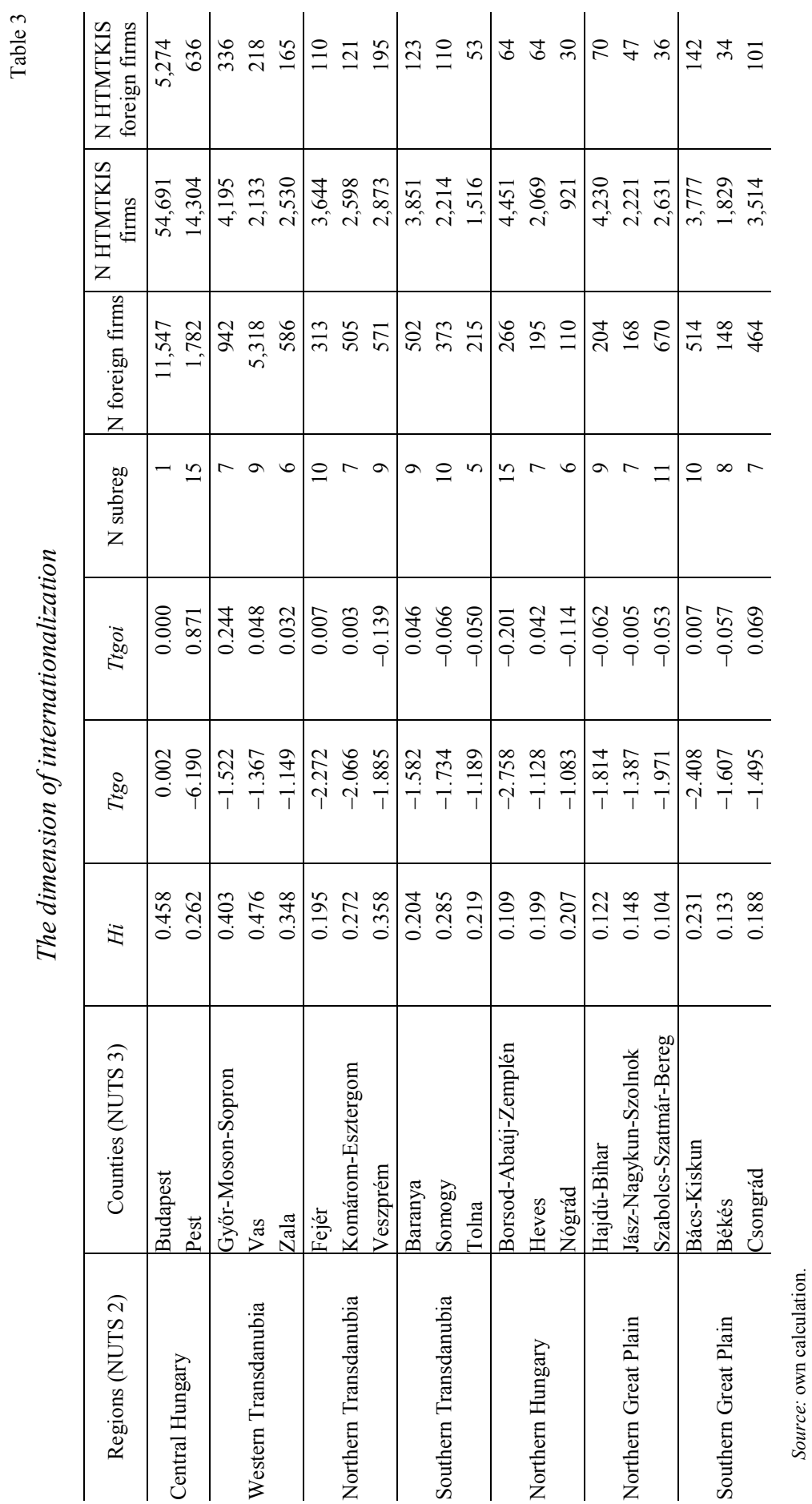


RIS synergy indicators (HTMTKIS sectors) and GDP per capita, 2005

Figure 5
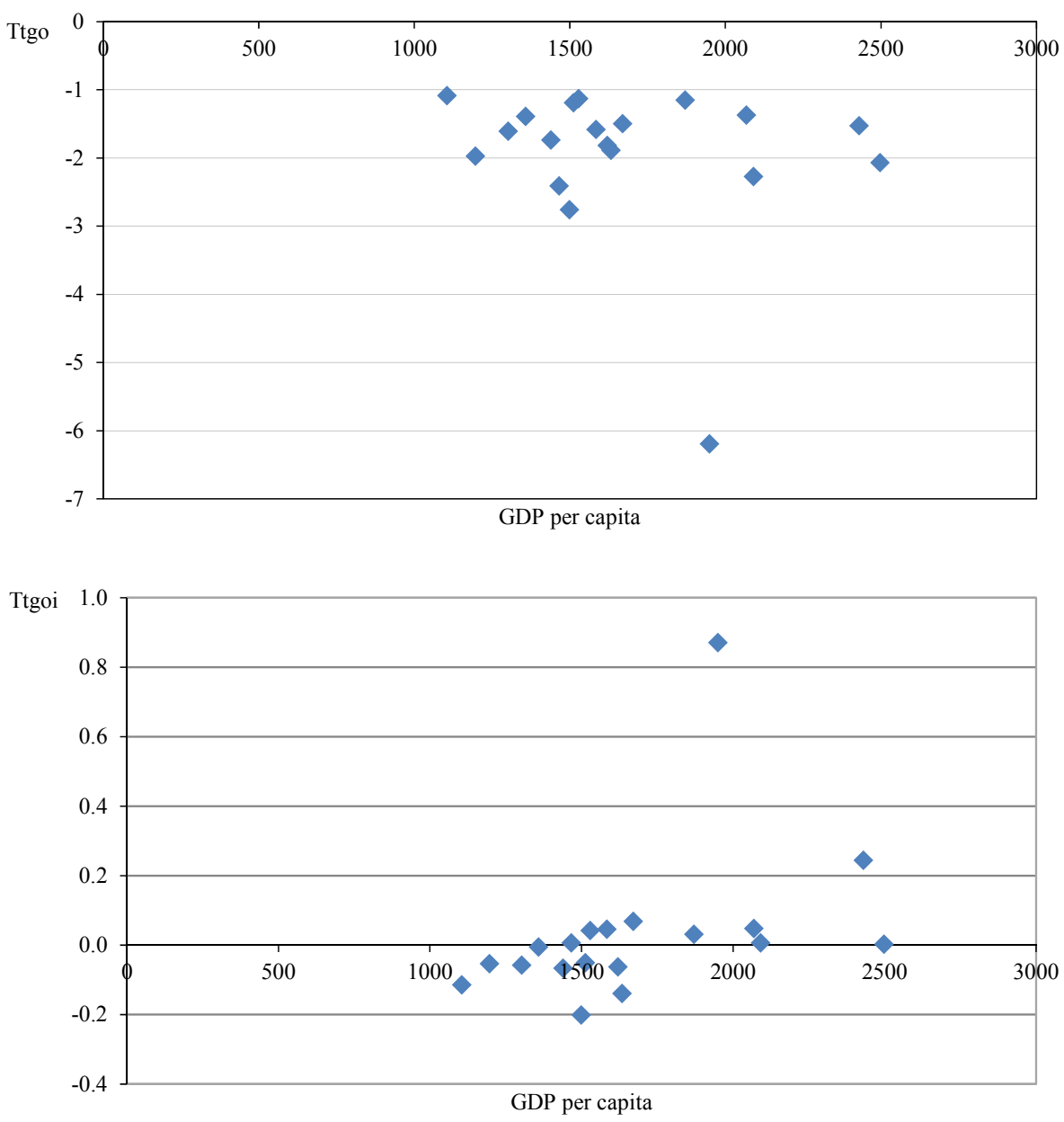

Source: own compilation.

Figure 5 depicts the association between GDP per capita and RIS synergy indicators. Note that the expected negative relation prevails between $T_{T G O}$ and GDP per capita, whereas the distribution of $T_{T G O I}$ indicator is associated positively with spatial differences in GDP per capita. The outlier region is Pest County in both $T_{T G O}$ and $T_{T G O I}$ distributions. The quantification of the statistical relationship highlights that GDP per capita is positive and significantly related to $T_{T G O I}$, meanwhile there is no statistically significant relation between GDP per capita and $T_{T G O}$ (Table 4). This major finding implies that internationalization is very important in calculating innovation systems synergy and associating the indicator with regional development. 
Correlation among RIS synergy indicators measured in HTMTKIS sectors and GDP per capita

\begin{tabular}{l|c|c|c}
\hline \multicolumn{1}{c|}{ Pearson/Spearman } & $T_{T G O}$ & $T_{T G O I}$ & GDP per capita \\
\hline$T_{T G O}$ & 1 & 0.122 & -0.163 \\
$T_{T G O I}$ & $-0.770^{\mathrm{a})}$ & 1 & $0.596^{\mathrm{a})}$ \\
GDP per capita & -0.201 & $0.402^{\mathrm{b})}$ & 1
\end{tabular}

Note: Pearson correlation values are below the diagonal and Spearman correlation values are above it. a) and b) denote statistical significance at the 0.01 and 0.05 levels, respectively.

Source: own calculation.

In summary, our results show that foreign firms have added to regional innovation system synergies in some areas but disturbed synergy in others. The map of HTMTKIS sectors is particularly interesting because the four-dimensional synergy is indicated in regions where above average development was reported in section 3 (see Figure 2). However, there is a lack of synergy - increasing uncertainty in four dimensions - in regions lagging behind in the eastern part of the country. Thus, internationalization is a very important dimension in regional innovation systems and synergy derived from fourdimensional firm distributions goes hand in hand with regional development in Hungary. Because the number of foreign-owned firms does not differ significantly across regions (as it was shown in Figure 2), the result suggests that not the presence of foreign firms per se but the synergies generated are important for regional development.

Internationalization of innovation systems and the appearance of foreign firms provide extra opportunities as well as challenges for regions. Systems synergies might be further enhanced if a region was successfully integrated into the global market by the local value chains or university relationships of present multinational companies. However, these firms can have negative effects on local synergies as well: domestic companies can be expelled from the market; talented labour might be exclusively pooled to MNEs, leaving no space for dynamic SMEs, etc. This latter phenomenon is discussed in the following subsection.

\section{Foreign firms' effect on innovation systems synergy}

Due to the decomposability of entropy measures, one can calculate the contribution of mutual information measured in sub-groups with the mutual information measured in the entire set. In order to do that, mutual redundancy in the subgroups has to be calculated in the same way as presented above and the share in the entropy measured in the whole set, weighted by the number of firms calculated. The contribution of three-dimensional mutual redundancy measured in foreign-owned and domestic subgroups to the mutual redundancy in the region is illustrated in Table 5. 


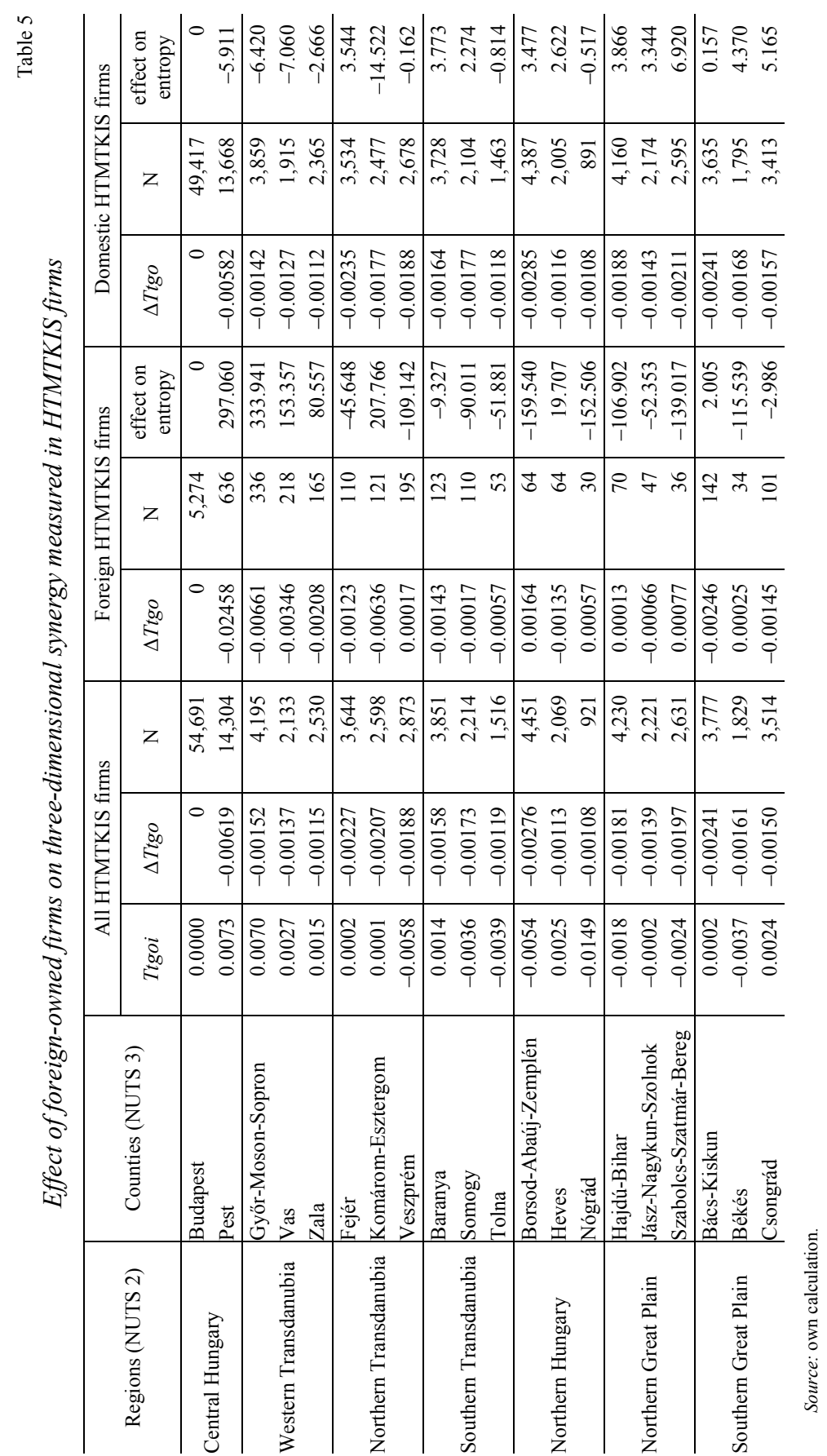


We found conflicting effects of foreign and domestic firms on regional innovation systems in several counties. On the one hand, the subgroup of foreign-owned firms adds to innovation systems synergy in seven counties only, but their effect seems to disturb systems synergy in the other 12 counties. On the other hand, the domestic group contributes to synergy in 12 counties and disturbs synergy in 7 counties. It is very important to note that the effects are not always mutually exclusive: for example, both subgroups have positive effects on synergy in Bács-Kiskun and Heves counties; both subgroups disturb synergies in Veszprém, Tolna, and Nógrád counties. Firm ownership effect on innovation systems synergy is depicted in Figure 5.

Effect of foreign and domestic companies on synergy, 2005

Figure 6
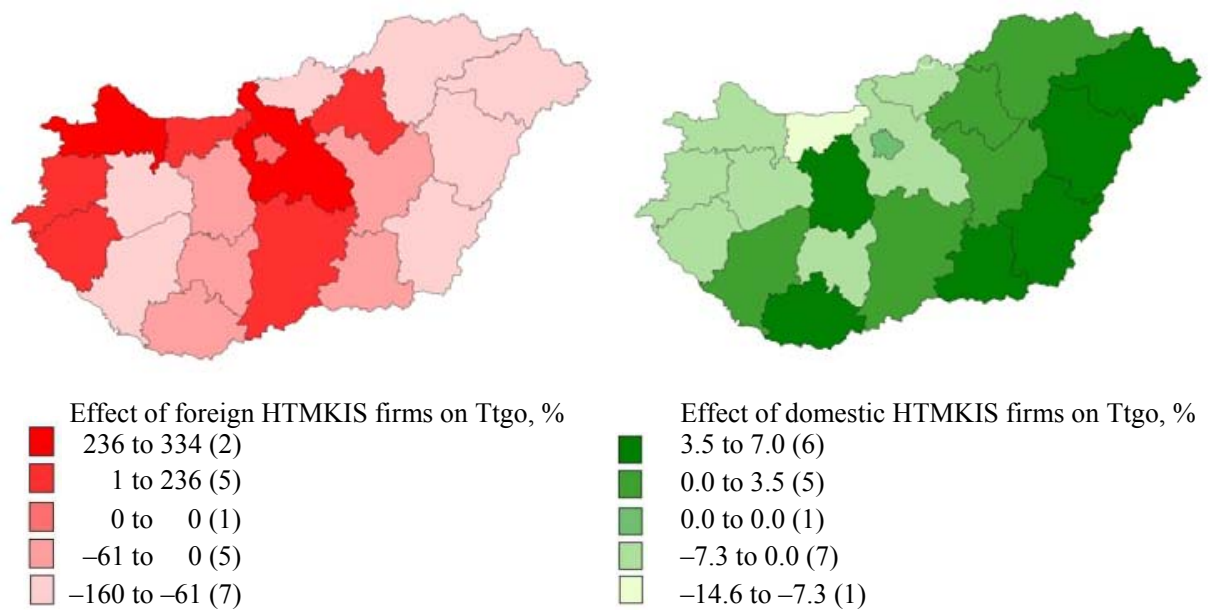

Effect of domestic HTMKIS firms on Ttgo, \% 3.5 to $7.0(6)$

0.0 to $3.5(5)$

0.0 to $0.0(1)$

-7.3 to $0.0(7)$

-14.6 to $-7.3(1)$

Source: own compilation.

Our findings suggest that a small set of foreign firms became the leading entities in the counties in the Northwest of the country. These counties experienced a positive effect on the synergy, but the other counties were affected negatively. The first group of counties performs above the national average of regional development. However, foreign HTMTKIS companies influence RIS synergy negatively in southern and eastern counties where domestic firms play the dominant role and have a positive effect on the synergy.

Consequently, regions have followed different paths regarding the establishment of synergistic economic systems, in which the diverse effect of foreign-owned firms has been a determining factor. Foreign-owned firms have generated new synergies in a limited number of relatively developed regions where the systems do not seem to self-organize in terms of domestic companies. In other regions, foreign-owned firms have disturbed the synergy that was established by domestic companies. This result is consistent with the questions raised and conjectures specified by Lengyel and Leydesdorff (2011); however, in this study, we provide the quantitative evidence for the effect of a dual economic structure on diverse regional development in Hungary. 


\section{Conclusion and discussion}

This study applied a synergy perspective to the analysis of the effect of foreign firms and FDI in regional innovation systems. We have introduced a four-dimensional model as a further development of innovation systems synergy measurement, in which the dimension of internationalization - using foreign versus domestic ownership - is taken into consideration as a new factor. We showed that RIS synergy derived from the fourdimensional model correlates with GDP per capita in regions whereas the threedimensional model did not. In general, internationalization and the appearance of foreign firms in regions is an important factor in describing the success of innovation systems.

However, we also find that foreign firms have diverse effects on local economies. Although foreign-owned firms have become major actors for regional development in Hungary, these firms did not always have a positive effect. On the one hand, our results suggest that foreign companies have contributed to establish synergy in RIS, but only in relatively more developed regions, for example, the regions around the capital and counties in the Northwest. A small set of foreign firms have restructured the innovation systems in these areas since synergy seems to have been established as an exclusive effect of foreign companies; the larger set of domestic firms disturbs synergy in these regions. On the other hand, foreign firms disturb synergy in the relatively lagging eastern and southern parts of the country, where the system is still self-organizing itself in terms of domestic companies. Thus, we find that FDI has had a diverse effect on regional innovation systems in Hungary.

Our results are policy-relevant, because Hungary and other Central and Eastern European countries have joined the EU and therefore also reformed their innovation policies in the 2000s accordingly (Suurna-Kattel 2010), despite the warnings of several scholars (Havas 2002, Radosevic-Reid 2006, von Tunzelmann-Nassehi 2004). Indeed, European policy standards might not work in the CEE context because foreign firms might have relatively stronger or even an exclusively dominant economic role, but also interact less with domestic companies in CEE countries than in other parts of Europe. Policies would have to be tuned accordingly (Lengyel-Cadil 2009, Lengyel et al. 2013, Rama 2008).

Based on the literature, one can claim that there is a huge demand for a refined innovation policy in CEE countries, and these policies will enhance technology transfer from multinational companies to domestic firms. A major finding of this paper implies that these refined instruments have to be decentralized and adjusted to regional innovation systems. Domestic companies may benefit more from the co-location of multinationals in those regions, where foreign firms have a positive effect on innovation systems synergies. Technology transfer from multinationals to domestic firms might have a chance in these relatively more developed territories only. In other areas, where foreign firms have a disturbing effect on synergy, there might be a lower chance for efficient technology transfer, and policies should rather focus on attracting appropriate investments.

Regional innovation systems are considered in our argument as complex economic systems that develop in a self-organizing manner when adapting to external interventions. We argue that dynamics in the system are led by a synergy among three innovation system functions: knowledge exploration, knowledge exploitation and organizational control. Further theoretical research is needed. 
Further studies can unfold the concordance of synergy measurement and other types of RIS theorizing. Two subsystems are distinguished in RIS literature: knowledge exploration subsystem (universities, PROs, etc.) and knowledge exploitation subsystem (companies, clusters, etc.); furthermore, their interaction, is enhanced by economic and science policies (Tödtling-Trippl 2005). A well functioning RIS equally draws on the two subsystems, and regional economic advantage can be constructed when government is involved as a third subsystem providing organizational control for the system (Cooke et al. 2004). Synergy measurement derived from the triple helix of university-industry-government model can enter the discussion at this point (Etzkowitz-Leydesdorff 2000). Since very different selection mechanisms operate in the three subsystems, the level of synergy or overlap among them can be expected to mark the innovative quality of the RIS. Furthermore, further studies may be able to specify the argument that connections to other RIS and international markets are crucial to avoid regional lock-in and too narrow local cooperations (Narula 2002, Tödtling-Tripple 2005).

More efforts are needed to connect the concept and measurement of innovation system functions to indicators in regional economics. Innovation system functions can also be explained in terms of localization economies, local competition, and urbanization economies in future studies. For example, the knowledge exploration indicator measures co-variation between geographical and technological distribution of firms; hence, it can monitor the operation of localization economies or, in other words, the extent to which companies of similar technological profiles co-locate in the region. Similarly, our indicator of knowledge exploitation measures co-variation between technologically and organizationally proximate firms in the region. This can lead to positive and negative externalities since these firms are more likely to learn from each other's complex organization-related issues. However, competition may also be more intense under the condition of intense knowledge exploitation.

The organizational control function in the innovation system organizes firms of similar sizes (regardless of technological profile) to co-locate. One can associate organizational control to urbanization economies because settlement structures may strongly affect the value of organizational control. In other words, large firms may be co-located in big cities while small firms tend to be co-located in small towns of the region, due to the size of the local market and labour force. We intend to shed light on relations between knowledge functions and localization economies, urbanization economies, and local competition in follow-up studies.

Acknowledgements

The work of Balazs Lengyel was supported by the Hungarian Scientific Research Fund (OTKA, PD106290).

\section{REFERENCES}

Acs, Z.-Anselin, L.-Varga, A. (2002): Patents and innovation counts as measures of regional production of knowledge Research Policy 31 (7): 1069-1085.

Acs, Z.-O'Gorman, C.-Szerb, L.-Terjesen, S. (2007): Could the Irish miracle be repeated in Hungary? Small Business Economics 28 (2-3): 123-142. 
Allen, P.M. (2001): Knowledge, ignorance and the evolution of complex systems In: Foster, J.-Metcalfe, J.S. (Eds.) Frontiers of evolutionary economics: competition, self-organization and innovation policy pp. 313-350., Edward Elgar, Cheltenham-Northampton.

Asheim, B.T.-Isaksen, A. (2002): Regional innovation systems: the integration of local „sticky” and global „ubiquitous” knowledge Journal of Technology Transfer 27 (1): 77-86.

Baum, J. A. C.-Li, S. X.-Usher, J. M. (2000): Making the next move: How experiential and vicarious learning shape the locations of chains' acquisitions Administrative Science Quarterly 45 (4): 766-801.

Békés, G.-Kleinert, J.-Toubal, F. (2009): Spillovers from multinationals to heterogeneous domestic firms: evidence from Hungary The World Economy 32 (10): 1408-1433.

Biggiero, L. (2007): The location of multinationals in industrial district: knowledge transfer in biomedicals Journal of Technology Transfer 27 (1): 111-122.

Blazek, J.-Uhlír, D. (2007): Regional innovation policies in the Czech Republic and the case of Prague: an emerging role of a regional level? European Planning Studies 15 (7): 871-888.

Braczyk, H.J.-Cooke, P.-Heidenreich, M. (1998): Regional Innovation Systems: The Role of Governance in a Globalized World UCL Press, London.

Boschma, R.-Frenken, K. (2006): Why is economic geography not an evolutionary science? Towards an evolutionary economic geography Journal of Economic Geography 6 (3): 273-302.

Cantwell, J.-Iammarino, S. (1998): MNCs, technological innovation and regional systems in the EU: some evidence from the Italian case International Journal of the Economics of Business 5 (3): 383-408.

Coase, R.H. (1937): The Nature of the Firm Economica 4 (16): 386-405.

Cooke, P. (2001): Regional innovation systems, clusters, and the knowledge economy Industrial and Corporate Change 10 (4): 945-974.

Cooke, P.-Heidenreich, M.-Braczyk, H.J. (2004): Regional Innovation Systems. Second Edition, The role of governance in a globalized world Routledge, London and New York.

Cooke, P.-Leydesdorff, L. (2006): Regional development in the knowledge-based economy: the construction of advantage Journal of Technology Transfer 31 (1): 5-15.

Dachs, B.-Ebersberger, B.-Lööf, H. (2008): The innovative performance of foreign-owned enterprises in small open economies Journal of Technology Transfer 33 (4): 393-406.

Delorme, R. (2001): Theorizing complexity In: Foster, J.-Metcalfe, J.S. (Eds.) Frontiers of evolutionary economics: competition, self-organization and innovation policy pp. 80-108., Edward Elgar, Cheltenham-Northampton.

Etzkowitz, H.-Leydesdorff, L. (2000): The Dynamics of Innovation: From National Systems and 'Mode 2' to a Triple Helix of University-Industry-Government Relations Research Policy 29 (2): 109-123.

Ferragina, A.M.-Mazzotta, F. (2014): FDI spillovers on firm survival in Italy: absorptive capacity matters! Journal of Technology Transfer 39 (6): 859-897.

Foster, J.-Metcalfe, J.S. (2001): Frontiers of evolutionary economics: competition, self-organization and innovation policy Edward Elgar, Cheltenham-Northampton.

Frenken, K.-van Oort, F.-Verburg, T. (2007): 'Related Variety, Unrelated Variety and Regional Economic Growth' Regional Studies 41 (5): 685-697.

Gibbons, M.-Limoges, C.-Nowotny, H.-Schwartzman, S.-Scott, P.-Trow, M. (1994): The new production of knowledge: The Dynamics of Science and Research in Contemporary Societies SAGE, London.

Halpern, L.-Muraközy, B. (2007): Does distance matter in spillover? Economics of Transition 15 (4): $781-805$.

Havas, A. (2002): Does innovation policy matter in a transition country? The case of Hungary Journal of International Relations and Development 5 (4): 380-402.

Hungarian Central Statistical Office (2007). National Accounts of Hungary, 2004-2005 Hungarian Central Statistical Office, Budapest. http://portal.ksh.hu/pls/ksh/docs/hun/xftp/idoszaki/monsz/monsz0405.pdf (downloaded from: 01. 08. 2015)

Inzelt, A. (2008): The inflow of highly skilled workers into Hungary: a by-product of FDI Journal of Technology Transfer 33 (4): 422-438.

Ivanova I.A.-Leydesdorff, L. (2014): A simulation model of the Triple Helix of university-industry-government relations and the decomposition of redundancy Scientometrics 99 (3): 927-948.

Jaffe A.B.-Trajtenberg M.-Henderson R. (1993): Geographic localization of knowledge spillovers as evidenced by patent citations Quarterly Journal of Economics 108 (3): 577-598. 
Jakulin, A. (2005): Machine learning based on attribute interactions University of Ljubljana, Ljubljana.

Johnston, R. J.-Gregory, D.-Pratt, G.-Watts, M. (2000): The Dictionary of Human Geography Blackwell, Oxford.

Krippendorff, K. (2009): Ross Ashby's information theory: a bit of history, some solutions to problems, and what we face today International Journal of General Systems 38 (2): 189-212.

Lengyel, B.-Cadil, V. (2009): Innovation policy challenges in transition countries: foreign business R\&D in the Czech Republic and Hungary Transition Studies Review 16 (1): 174-188.

Lengyel, B.-Leydesdorff, L. (2011): Regional innovation systems in Hungary: The failing synergy at the national level Regional Studies 45 (5): 677-693.

Lengyel, B.-Sebestyén, T.-Leydesdorff, L. (2013): Challenges for regional innovation policies in CEE countries: spatial concentration and foreign control of US patenting Science and Public Policy 42 (1): 1-14.

Lengyel, B.-Szakálné Kanó, I. (2014): Regional growth in a dual economy: ownership, specialization and concentration in Hungary Acta Oeconomica 64 (3): 257-285.

Leydesdorff, L.-Dolfsma, W.-van der Panne, G. (2006): Measuring the knowledge base of an economy in terms of Triple Helix relations among 'technology, organization, and territory' Research Policy 35 (2): 181199.

Leydesdorff L.-Fritsch M. (2006): Measuring the knowledge base of regional innovation systems in Germany in terms of a Triple Helix Dynamics Research Policy 35 (10): 1538-1553.

Leydesdorff, L.-Ivanova, I. A. (2014): Mutual Redundancies in Inter-human Communication Systems: Steps Towards a Calculus of Processing Meaning Journal of the Association for Information Science and Technology 65 (2): 386-399.

Leydesdorff, L.-Park, H. W.-Lengyel, B. (2014): A Routine for Measuring Synergy in University-IndustryGovernment Relations: Mutual Information as a Triple-Helix and Quadruple-Helix Indicator Scientometrics 99 (1): 27-35.

Leydesdorff, L.-Perevodchikov, E.-Uvarov, A. (2015): Measuring Triple-Helix Synergy in the Russian Innovation Systems at Regional, Provincial, and National Levels Journal of the Association for Information Science and Technology 66 (6): 1229-1238.

Leydesdorff, L.-Strand, Ø. (2013): The Swedish system of innovation: regional synergies in a knowledge-based economy Journal of the Association for Information Science and Technology 64 (9): 1890-1902

Leydesdorff, L.-Sun, Y. (2009): National and International Dimensions of the Triple Helix in Japan: UniversityIndustry-Government versus International Co-Authorship Relations Journal of the American Society for Information Science and Technology 60 (4): 778-788.

Loasby B. J. (2001): Time, knowledge and evolutionary dynamics: why connections matter Journal of Evolutionary Economics 11 (4): 393-412.

Louca, F. (2001): Measuring complexity: puzzles and tentative solutions In: Foster, J.-Metcalfe, J.S. (Eds.) Frontiers of evolutionary economics: competition, self-organization and innovation policy pp. 278306., Edward Elgar, Cheltenham-Northampton.

Lundvall, B.-Å.-Johnson, B.-Andersen, E.S.-Dalum, B. (2002): National Systems of Production, Innovation and Competence Building Research Policy 31 (2): 213-231.

Majumdar, S.K. (2009): Technology transfer by foreign firms and the utilization of competencies within Indian industry Journal of Technology Transfer 34 (1): 95-117.

March, J.G. (1991): Exploration and exploitation in organizational learning Organization Science 2 (1): $71-87$.

Martin, R.-Sunley, P. (2007): Complexity thinking and evolutionary economic geography Journal of Economic Geography 7 (5): 573-601.

McGill, W. J. (1954): Multivariate information transmission Psychometrika 19 (2): 97-116.

Mêgnigbêto, E. (2014): Efficiency, unused capacity and transmission power as indicators of the Triple Helix of university-industry-government relationships Journal of Informetrics 8 (1): 284-294.

Metcalfe, J. S.-Foster, J. (2004): Evolution and Economic Complexity Edward Elgar, Cheltenham-Northampton.

Narula, R. (2002): Innovation systems and 'inertia' in R\&D location: Norwegian firms and the role of systemic lock-in Research Policy 31 (5): 795-816.

Radosevic, S. (2002): Regional Innovation Systems in Central and Eastern Europe: Determinants, Organizers and Alignments Journal of Technology Transfer 27 (1): 87-96.

Radosevic, S.-Reid, A. (2006): Innovation policy for a knowledge-based economy in Central and Eastern Europe: driver of growth or new layer of bureaucracy? In Piech, K.-Radosevic, S. (Eds.) The knowledge-based 
economy in Central and Eastern European countries: countries and industries in a process of change pp. 295-313., Palgrave McMillan, London.

Rama, R. (2008): Foreign investment innovation: a review of selected policies Journal of Technology Transfer 33 (4): 353-363.

Shannon, C.E. (1948): A Mathematical theory of communication Bell System Technical Journal 27: 379-423 and 623-656.

Storper, M. (1997): The Regional World - Territorial Development in a Global Economy Guilford Press, New York

Strand, Ø.-Leydesdorff, L. (2013): Where is synergy indicated in the Norwegian innovation system? Triple-Helix relations among technology, organization, and geography Technological Forecasting and Social Change 80 (3): 471-484.

Suurna, M.-Kattel, R. (2010): Europeanization of innovation policy in Central and Eastern Europe Science and Public Policy 37 (9): 646-664.

Theil, H. (1972): Statistical Decomposition Analysis North-Holland, Amsterdam and London.

Tödtling, F.-Trippl M. (2005): One size fits all? Towards a differentiated regional innovation policy approach Research Policy 34 (8): 1203-1219.

von Tunzelmann, N.-Nassehi, S. (2004). Technology policy, European Union enlargement, and economic, social and political sustainability Science and Public Policy 31 (6): 475-483.

Ulanowicz, R. E. (1986): Growth and Development: Ecosystems Phenomenology Springer-Verlag, New York. Ulanowicz, R. E. (2009): The dual nature of ecosystem dynamics Ecological modelling 220 (16): 1886-1892.

Yeung, R. W. (2008): Information Theory and Network Coding Springer, New York. 